\title{
Descolonizando a psicologia: notas para uma Psicologia Preta
}

\author{
Lucas Motta Veiga (D) \\ Universidade Federal Fluminense, Niterói, RJ, Brasil
}

\begin{abstract}
Resumo
O presente artigo investiga os efeitos da colonização na produção de subjetividade e na produção de conhecimento, em especial seu desdobramento na formação dos profissionais de psicologia. Com o objetivo de demonstrar a fragilidade da formação em psicologia no Brasil e os impactos do racismo nas subjetividades negras, o artigo apresenta epistemologias do campo da saúde mental historicamente apagadas nos currículos das graduações. Resgatamos o trabalho de Wade Nobles, Naim Akbar, Neusa Santos Sousa, dentre outros intelectuais negros e negras para, numa articulação com nossa experiência clínica, apontar como as subjetividades negras podem ser cuidadas em sua singularidade. Concluímos que o cuidado da saúde mental da população negra brasileira não pode se dar sem um resgate epistemológico das produções negras sobre o tema, e que a dimensão de aquilombamento que é instaurada na clínica quando do atendimento de pacientes negros por psicólogos negros é fundamental na promoção de saúde mental da população negra. Finalizamos estabelecendo direções clínico-políticas para a expansão de uma Psicologia Preta no Brasil.
\end{abstract}

Palavras-chave: colonização; Psicologia Preta; saúde mental.

\section{Decolonizing psychology: notes for a Black Psychology}

\begin{abstract}
This article investigates the effects of colonization on the production of subjectivity and on the production of knowledge, especially its development in the training of psychology professionals. In order to demonstrate the fragility of the training in psychology in Brazil for the treatment of the impacts of racism on black subjectivities, the article presents mental health epistemologies historically erased in the curricula of the graduations. We have retaken the work of Wade Nobles, Naim Akbar, Neusa Santos Sousa, among other black intellectuals and articulated it with our clinical experience to address black subjectivities and how they can be taken care of considering all their singularity. We have concluded that we cannot take care of Brazilian black population's mental health without an epistemological retake of black intellectual work on the subject and that the quilombola dimension instated in the clinical environment when black psychologists take care of black patients is essential in the mental health promotion of black population. We finalized stablishing clinical and political directions to an expansion of a Black Psychology in Brazil.
\end{abstract}

Keywords: colonization; Black Psychology; mental health.

\section{Introdução}

É imprescindível ao psicólogo estar atento e sensível ao contemporâneo. É tempo de ampliarmos cada vez mais a concepção de que o que se passa no mundo nos atravessa e produz subjetividade (GUATTARI, 1992). O sofrimento psíquico não é da ordem da intimidade, ele é político. A histeria tal como Freud tratou e a que ainda comparece em nossos consultórios existiria em um mundo em que não houvesse opressão de gênero e das manifestações da sexualidade? Emmy Von N., primeira paciente de Freud, pede a ele que fique em silêncio e a escute (BREUER; FREUD, 1895/1995). Pediu a um homem branco no seu lugar de poder/saber médico que parasse com suas técnicas, hipnose e sugestão na época, e a ouvisse. Podemos parafraseá-la e dizer: "respeite meu lugar de fala, encontre seu lugar de escuta". Desde então, a escuta vem sendo vivida como principal tecnologia terapêutica de diferentes abordagens clínicas. Conseguir ouvir o paciente implica conseguir ouvir o sintoma que o adoece, ouvir o sintoma para ouvir o mundo que o produz. Dar poucos ouvidos ao mundo talvez tenha sido um dos grandes erros da história da psicanálise.

Nietzsche (1882) ouviu e decretou a morte de Deus. Sacou que uma virada num dos eixos de sustentação do mundo tal como ele é estava se dando. E que era preci-

\footnotetext{
^Endereço para correspondência: Universidade Federal Fluminense, Instituto de Psicologia, Campus do Gragoatá. Rua Professor Marcos Waldemar de Freitas Reis, $\mathrm{s} / \mathrm{n}^{\circ}$, bloco N, $4^{\circ}$ andar. São Domingos - Niterói, RJ - Brasil. CEP: 24210 201.E-mail: lucasmottaveiga@gmail.com

Os dados completos do autor encontram-se ao final do artigo.
}

so seguir afirmando esta morte, trabalhar para que ela seguisse se efetuando. $\mathrm{O}$ que os ouvidos sensíveis do contemporâneo podem ouvir? É tempo de decretarmos o fim do colonialismo. Sair da grande noite, operar a descolonização radical de Fanon (MBEMBE, 2017). Como psicólogo, me interessa sobremaneira a descolonização do inconsciente. Nosso inconsciente é colonial. O sucesso da colonização se baseia na capacidade não apenas de colonizar territórios geográficos, mas na capacidade também de colonizar territórios existenciais, o inconsciente. Racismo, machismo, lgbtfobia são produtos da máquina colonial de produção de subjetividade, produtos que operam um corte na realidade e que dividem o mundo num arranjo que compõe quem exerce violência e quem a sofre. Opressão do branco sobre o negro, do homem sobre a mulher, do cis sobre a/o trans, do hétero sobre o homossexual. Este mundo tal como o conhecemos se funda na violência.

Numa sociedade estruturada na violência, sua reestruturação não pode se dar senão por meio do que Mombaça (2016) chamou de "redistribuição da violência". Mas, diferente do modo destruidor da violência colonial, a violência anticolonial é uma violência criadora. Em se tratando da questão racial, a redistribuição dessa violência começa com a violência da marca. Você é branco. Nomear o branco de branco, marcar que o lugar de onde ele fala é o de uma pessoa branca, que os autores que ele lê são brancos, que o pensamento dele é branco. Fazer isso sem subjugar a ele e aos seus um regime de escravidão, fazer isso sem que seus jovens brancos sejam assassina- 
dos a cada 23 minutos no Brasil. Apenas marcar: você é branco. A esse respeito, Mignolo (2008, p. 297) afirma que "ao ligar a descolonialidade com a identidade em política, a opção descolonial revela a identidade escondida sob a pretensão de teorias democráticas universais".

Em se tratando da formação e do exercício da psicologia no Brasil, promover sua descolonização também parte por marcar que a psicologia brasileira é branca (VEIGA, 2018a). Tendo sido colonizados por uma branquitude-patriarcal-europeia, ficou identificado como sendo bom, inteligente ou relevante a criação do colonizador, inclusive e, talvez principalmente, sua produção de conhecimento. Como desdobramento dessa colonização do pensamento, homens-brancos-europeus foram tomados como sabedores das questões filosóficas, existenciais, políticas, econômicas, artísticas e psicológicas de todos os povos. O pensamento colonial é universalista, mas nega que o seja como um ato de resistência sintomático de negação da própria doença.

Os currículos de psicologia nas universidades brasileiras são impregnados de colonialismo, e os autores mais estudados são homens-brancos-europeus. Estes autores, que são importantes na história ocidental da psicologia como ciência, e aqui me refiro à psicologia clínica, construíram conceitos para manejar as subjetividades brancas com foco no sofrimento psíquico. A importação e incorporação direta das conceituações psicológicas e psicanalíticas produzidas na Europa desconsideram a singularidade da marca, dos processos de subjetivação não-brancos e impõem uma nosologia à imagem e semelhança da subjetividade do colonizador. A esse respeito, nos diz Abdias Nascimento:

Como poderiam as ciências humanas, históricas - etnologia, economia, história, antropologia, sociologia, psicologia e outras - nascidas, cultivadas e definidas para povos e contextos socioeconômicos diferentes, prestarem útil e eficaz colaboração ao conhecimento do negro, à sua realidade existencial, aos seus problemas, aspirações e projetos? Seria a ciência social elaborada na Europa e nos Estados Unidos tão universal em sua aplicação? (NASCIMENTO, A., 2009, p. 206).

Ao limitar-se às conceituações brancas e europeias sobre saúde mental e sofrimento psíquico, a psicologia brasileira deixa de contemplar e tratar adequadamente $54 \%$ da população do país, composta por negros e negras. A subjetividade negra é ignorada na grande maioria das graduações em psicologia, e um dos efeitos diretos disso são pacientes negros serem vítimas de racismo pelos profissionais que deveriam acolhê-los e, ao mesmo tempo, sentirem que não estão sendo compreendidos em suas questões e nem escutados como pertencentes a um povo que durante mais de 300 anos foi escravizado e que só há 130 anos foi liberto.

Diversos intelectuais negros e negras dedicaram-se à produção de conhecimento sobre os efeitos do racismo nas subjetividades negras. Já na década de 1930 a psicanalista Virgínia Bicudo realizou uma vasta pesquisa com negros em São Paulo, que resultou na sua dissertação de mestrado Atitudes raciais de negros e mulatos em São Paulo. O psiquiatra martinicano Frantz Fanon, em seu trabalho clínico e acadêmico, escreveu, nos anos 1940, o livro Pele negra, máscaras brancas, referência nos estudos da saúde mental da população negra. Nos anos 1960/1970, no trabalho de psicólogos negros como Wade Nobles e Naim Akbar surge, nos Estados Unidos, a Black Psychology como sendo a construção de teorias e práticas em psicologia clínica tendo como referência as subjetividades negras e a ancestralidade africana. Nos anos 1980, a psicóloga e psicanalista brasileira Neusa Santos Souza escreveu o livro Tornar-se negro, em que fez uma releitura de conceitos fundamentais da psicanálise a partir da experiência negra. Não há espaço aqui para o levantamento de todas as publicações sobre saúde mental negra ao longo da história; elegemos essas por se tratar de publicações de autores e autoras pioneiros nesse tema.

\section{A saúde mental de vidas negras importa}

A subjugação dos africanos à condição de escravos produziu efeitos devastadores em suas subjetividades. Para além das mortes nos porões dos navios, nas rebeliões, nos castigos perpetrados pelos colonizadores, muitos africanos em condição de escravidão atentaram contra a própria vida. A retirada forçada de sua terra, de sua comunidade, de sua língua, de seus laços afetivos e a subsequente diáspora pelo mundo na condição de escravos teve efeitos de desterro e de perda de referências tão acentuados, que a própria identidade e consciência corporal entravam num processo de desintegração. Resgatar a cultura africana por meio do canto, da dança e da espiritualidade foi fundamental na preservação da saúde mental dos africanos. As fugas e construções de quilombos garantiram o restabelecimento do senso de identidade e de coletividade permitindo que, por piores que fossem as condições de vida, muitos sobrevivessem e inscrevessem em terras brasileiras as heranças culturais da África.

Como descendentes de africanos nascidos pós-abolição, e ainda que não tenhamos vivido os horrores da escravidão do modo como nossos ancestrais viveram, trazemos as marcas desse período. Para além disso, estamos inseridos num país que implementou e que perpetua com múltiplos dispositivos uma política de embranquecimento da população. Política esta que se inaugura com a abertura do país para a entrada de imigrantes europeus no fim do século 19 a fim de substituir a mão de obra escrava e que se desdobra até os dias de hoje onde a cada 23 minutos um jovem negro é assassinado; em que a expectativa de vida dos negros é de seis anos a menos que a dos brancos; em que $75 \%$ da população mais pobre é negra; em que a renda per capita de famílias negras é 200\% menor que a renda de famílias brancas; em que, apesar de ser mais de $54 \%$ da população nacional, negros são minoria no Congresso, na Academia, na Televisão e em todos os espaços de poder da sociedade (CARNEIRO, 2011).

Vivemos num país antinegro, e isto tem efeitos nocivos sobre as subjetividades negras. O termo subjetividade, aqui, refere-se à produção de modos de ser, estar, sentir e perceber o mundo (VEIGA, 2015). São inúmeros os vetores que se atravessam na constituição das subjetividades; e o racismo é um desses vetores que, nas subje- 
tividades negras, é o catalisador dos demais, a partir do qual toda uma configuração existencial é montada. Neusa Santos Souza (1983, p. 6) fala do efeito do racismo na relação do negro com o próprio corpo:

A partir do momento em que o negro toma consciência do racismo, seu psiquismo é marcado com o selo da perseguição pelo corpo-próprio. Daí por diante, o sujeito vai controlar, observar, vigiar este corpo que se opõe à construção da identidade branca que ele foi coagido a desejar. A amargura, desespero ou revolta resultantes da diferença em relação ao branco vão traduzir-se em ódio ao corpo negro.

De acordo com a psicanalista, o branco como ideal e como marca do desejo faz com que o negro se engaje em formas de se aproximar desse ideal branco, aproximação que tem como objetivo e como efeito apagar os signos corporais do corpo negro, afilar seus traços como alisar ou raspar os cabelos, e, no limite, desejar o apagamento total do corpo negro, sua própria extinção. Veremos mais adiante os efeitos do racismo nos corpos-subjetividades negras.

A saída forçada da África e a vida num país antinegro são elementos que se entrecruzam na produção da subjetividade negra. Chamo de "efeito diáspora" a sensação de não se sentir pertencente ao ambiente onde se vive, a dificuldade de ser genuinamente acolhido e incluído nas dinâmicas sociais numa posição equânime com os demais membros da sociedade e não numa posição de subalternidade.

A experiência da negritude é marcada pelo desprezo e pelo ódio que a branquitude projetou sobre as vidas negras desde a escravidão até os dias de hoje. Ódio que, introjetado nas subjetividades negras, resulta num doloroso processo de auto-ódio. Essa engrenagem subjetiva de introjetar o afeto do outro como sendo seu é muito semelhante ao que se dá com uma vítima de abuso ou outra violência. A vítima, por vezes, sente-se culpada pelo ocorrido quando o afeto de culpa deveria ficar com o abusador. Culpa e auto-ódio atravessam na dolorosa experiência de elaboração do trauma de uma violência. Os abusos do racismo sobre os corpos e as subjetividades negras têm como um de seus efeitos a culpa pela condição socioeconômica precária em que a maior parte da população negra se encontra; e o auto-ódio por toda a raça negra e por si mesmo por sentir-se falho, menor, sem qualidades diante dos privilégios da branquitude.

Uma direção de tratamento para a cura desses afetos que corroem a subjetividade negra está em devolver para a branquitude, ou seja, para o abusador, a responsabilidade pela violência do racismo. O movimento de deslocamento da posição de auto-ódio para a posição de empoderamento passa pela experimentação do afeto de raiva como sendo o trilho pelo qual o que ficou represado e introjetado na subjetividade negra culpando-a pela condição em que se encontra e fazendo-a sentir-se inferior possa escoar por toda a malha subjetiva do tecido social. A subjetividade negra, liberta do auto-ódio, ganha espaço para a construção de outras relações consigo, com os demais negros, com a branquitude; a sensação permanente de não se sentir em casa, em vez de ser paralisante, se tor- na motor para a criação de modos singulares de existência diaspórica e matéria-prima para a produção artística, cultural, intelectual e política.

Como tratar dos efeitos do racismo na subjetividade negra numa relação terapêutica em que a marca do terapeuta, ser branco, é o que legitima as violências ao ser preto do paciente? Como acessar o auto-ódio para dele poder sair e não acessá-lo e dele continuar padecendo? Os psicólogos brancos suportariam a redistribuição da violência racial no setting? Quando a transferência negativa é, na verdade, violência criadora, o psicólogo branco sabe manejar? Questões fundamentais para promovermos a descolonização da psicologia e da prática clínica, posto que descolonizar não é apenas incluir na bibliografia as epistemologias até então silenciadas, mas colocar em questão o próprio lugar do psicólogo, situar suas marcas, seu lugar de fala, porque é desse lugar que ele exerce a escuta. Há uma dimensão da subjetividade negra que só outro negro consegue acolher. Um negro, diz Molefi Asante (2009, p. 102), “é uma pessoa que participou dos quinhentos anos de resistência à dominação europeia". Devido aos efeitos dos privilégios de se ter uma pele branca na subjetividade dos psicólogos brancos, a problemática do sofrimento racial, que maltrata as subjetividades negras, não é compreendida ou escutada com todas as suas implicações. "A alma do branco está corrompida", alerta-nos Fanon (2008, p. 118).

No filme Praça Paris (2018), de Lucia Murat, isso é ilustrado por meio da relação da terapeuta branca $\mathrm{Ca}$ mila com a paciente negra Glória. Camila não entende o caso de Glória. Sua escuta está tão embranquecida, que sua empatia é dirigida às pessoas brancas que aparecem no discurso de Glória. Incapaz de sintonizar com o sofrimento de uma mulher negra da favela, a psicóloga branca e, ironicamente, portuguesa, incomoda-se com a forma de Glória estar no mundo sem compreender que aquela forma era efeito do racismo e que era exatamente essa forma de ser que, na relação terapêutica ela precisaria mais do que acolher, suportar. Brancos, em geral, não suportam. Não sabendo lidar com o caso de Glória, Camila abandona-a, rejeita-a, reproduzindo em Glória aquilo que ela mais teme, aderindo totalmente ao sintoma da paciente a ponto de a experiência terapêutica de Glória se tornar mais uma das experiências traumáticas em série. Mas a direção cinematográfica faz com que Glória seja a antagonista e não Camila. Quando, diante do abandono da terapeuta, Glória procura seu endereço e vai até sua casa pedir que Camila não pare de atendê-la, a trilha sonora escolhida é a de um thriller; e quando Camila expulsa Glória de sua casa, a câmera foca em Camila, que corre para pegar um ansiolítico e um copo d'água. Não sabemos como foi o caminho de Glória de volta para casa. Olhos brancos sempre atentos às dores brancas.

\section{Como curar a negritude dos efeitos do racismo?}

Ainda que nós, negros nascidos pós-abolição, não tenhamos vivido o horror da escravidão, vivemos o horror do embranquecimento. Como o embranquecimento se dá a partir da negação do valor da pessoa negra e se perpetua 
por meio de um aparato político-midiático em que pessoas brancas estão na posição de poder e de referência da beleza, em detrimento às pessoas negras, surge, no negro, o desejo de se aproximar da brancura (NOBLES, 2009, p. 288). Esta introjeção da política de embranquecimento nacional nas subjetividades pretas cria uma condição psicológica debilitante, porque aquilo que ele é e do qual não pode se desfazer, a cor da pele, coloca-o socialmente numa posição subalterna. Tanto Neusa Santos Souza (1983) quanto Wade Nobles (2009) concordam que o embranquecimento é o principal alimento do auto-ódio. Um ataque que não se restringe à autoimagem e à autoestima negra e que deturpa o próprio sentido do que significa ser humano. A isso pode se seguir na pessoa negra um conjunto de comportamentos autodestrutivos que são, na verdade, "fugas psíquicas de uma realidade profundamente antinegra" (NOBLES, 2009, p. 290).

Nobles desenvolveu um conceito fundamental para a prática clínica de psicólogos pretos com pacientes pretos: pulsão palmarina. A pulsão palmarina, cujo nome faz referência a Zumbi dos Palmares, é o desejo de ser africano e livre. Livre das engrenagens coloniais que nos mantêm presos a um esquema sociopolítico que nos adoece, nos mata, nos afasta da realidade do que somos, nos afasta do sentido africano do que significa ser humano: "Ser humano é ser um espírito em contato constante com os poderes espirituais que habitam o invisível, é ser expressão singular da infinitude e da força do divino" (NOBLES, 2009, p. 292). Somos parte de uma totalidade cósmica e espiritual que rege o universo, somos elementos da natureza do mundo; nosso corpo é recipiente e instrumento de uma força espiritual em eterna expansão. Em diálogo com o conceito de pulsão palmarina, desenvolvido por Nobles, está o conceito de "ritmo" tal como apresentado por Naim Akbar (1975). Considerando que o eu africano é um eu extenso, ou seja, que o eu é a parte individualizada de uma totalidade originariamente divina, o ritmo seria o movimento que leva as pessoas negras a buscar formas de se reconectar com a dimensão coletiva de sua origem divina. O ritmo, de acordo com o psicólogo, é uma característica que os africanos do continente e da diáspora trazem geração após geração de seus ancestrais pela via da memória do corpo e de uma possível transmissão genética. É o ritmo que promove a reunião entre africanos e a criação de práticas coletivas que têm por finalidade expandir o eu individual no contato com os demais e possibilitar a reconexão com o divino que nos constitui e nos transborda, fazendo desaparecer momentaneamente a fragmentação e a separação entre os indivíduos. Naim Akbar (1975) afirma que a partir da noção de ritmo podemos compreender a força das manifestações culturais africanas na música, na dança, no candomblé. "A motivação básica do eu africano é um esforço por algo que vai além da individualidade e reconecta o eu com o eu extenso" (AKBAR, 1975, p. 98). A reconexão com o divino - o sentido africano do que significa ser humano - por meio de práticas coletivamente criadas é,

Fractal, Rev. Psicol., v. 31 - n. esp., p. 244-248, set. 2019 historicamente, condição de possibilidade da manutenção da saúde mental negra em meio às violências da colonização e do racismo.

\section{A colonização e seus desdobramentos}

A escravidão e o embranquecimento nos afastaram nós, negros - de nossas origens, não apenas por meio do apagamento dos caminhos e de parte da história de nossos ancestrais, mas também por meio da criação de uma narrativa sobre nós, que teve como efeito sentirmos vergonha, culpa, falta em relação a nós mesmos e ao povo ao qual pertencemos. But time's up. Esse tempo acabou. "A descolonização", diz Fanon, "é uma força de recusa, uma capacidade de dizer não" (MBEMBE, 2017, p. 185). Dizemos não às narrativas brancas e hegemônicas e traçamos nossas próprias narrativas a partir do trabalho que nossos ancestrais e nossos mais velhos em vida vêm produzindo ao longo dos séculos. Dizemos não a uma certa psicologia, branca demais para acolher e tratar dos efeitos do racismo em nossas subjetividades, e nos aprofundamos no estudo para o desenvolvimento de uma Psicologia Preta no Brasil.

Descolonizar implica estilhaçar as velhas sedimentações culturais, intelectuais e políticas e, mais do que resgatar, criar um senso de valor próprio sobre si mesmo e sobre o povo ao qual se pertence. Pertencemos ao povo que criou a matemática, a filosofia, a medicina, o samba, o jazz, o blues, o rap, o funk, o vogue, o hip hop, as pirâmides do Egito... "Eu sou dádiva, mas me recomendam a humildade dos enfermos" (FANON, 2008, p. 126). Experimentar a si mesmo como dádiva, seguir a recomendação de Oxum, que, ao ser perguntada sobre como encontrar o amor verdadeiro, respondeu: "olhando sempre para o espelho". O racismo produziu uma autoimagem turva, prejudicando a mais fundamental capacidade de amar: o amor-próprio. Uma das direções de trabalho na Psicologia Preta é promover o resgate do amor por si mesmo, por sua história, pelo povo ao qual se pertence.

$\mathrm{O}$ resgate da autoestima e do senso de valor de sua história e de seu povo não é suficiente para expurgar os efeitos do racismo na subjetividade e no cotidiano dos negros e negras. Pensar que se livrar das mazelas que o racismo produz é um trabalho apenas psicológico é perder de vista toda a engrenagem social que perpetua a supremacia branca e reproduz violências aos corpos negros. Destruir o racismo implica destruir o mundo tal como ele se encontra agora. O trabalho sobre si, o autocuidado - tão importante para que sigamos com saúde mental num mundo que quer nos exterminar - é ferramenta de fortalecimento para o confronto permanente com a realidade social do racismo.

Como negros, vivemos no exercício de driblar à exaustão e de não sucumbir à tristeza que este mundo branco gera em nós. Para nós não há saídas fáceis, nem rotas de fuga tranquilas. Há um trabalho permanente de confronto com o mundo, confronto que se dá simplesmente por existirmos. Ignorar o confronto é uma forma de resignar-se, um jeito de morrer aos poucos, bem devagarinho, enquanto o racismo vai sugando nossa energia vital. Olhar de frente para o confronto, assumi-lo, 
é espalhar granadas por todo o tecido social, provocar explosões micro e macropolíticas, desestabilizar a política, a economia, a universidade, a rua, a religião, a mídia. Perfurar a branquitude com os ossos da fratura exposta que o racismo produziu em nós e ver o sangue branco se misturar ao nosso sangue negro até que ambos fiquem vermelhos. Até que possamos, verdadeiramente, caminhar juntos, em pé de igualdade (VEIGA, 2018b).

\section{Considerações finais}

Efetuar a expansão de uma Psicologia Preta no Brasil é uma experiência de aquilombamento. Os quilombos foram dispositivos fundamentais na preservação da identidade, da dignidade, da cultura e da saúde mental da população negra (NASCIMENTO, B., 1985). Uma clínica preta, que se inicia no encontro entre psicólogos negros e negras e pacientes negros e negras, tem efeitos subjetivos semelhantes aos dos quilombos construídos por nossos ancestrais. $\mathrm{O}$ encontro entre profissionais negros para revisitar as bibliografias e produzir conhecimento sobre as subjetividades negras, bem como para supervisões clínico-institucionais coletivas é também estratégia de aquilombamento dentro do meio profissional e acadêmico ainda predominantemente branco da psicologia no Brasil. O encontro entre negros e negras é cura.

\section{Informações sobre o autor:}

Lucas Motta Veiga

(iD) https://orcid.org/0000-0002-9970-8468

(9) http://lattes.cnpq.br/1903105047792118

Psicólogo, Mestre em Psicologia e Estudos da Subjetividade pela Universidade Federal Fluminense.

Como citar este artigo:

\section{ABNT}

VEIGA, Lucas Motta. Descolonizando a psicologia: notas para uma Psicologia Preta. Fractal: Revista de Psicologia - Dossiê Psicologia e epistemologias contra-hegemônicas, Niterói, v. 31, n. esp., p. 244-248, set. 2019. https://doi.org/10.22409/1984-0292/ v31i esp/29000

\section{APA}

Veiga, L. M. (2019, set.). Descolonizando a psicologia: notas para uma Psicologia Preta. Fractal: Revista de Psicologia - Dossiê Psicologia e epistemologias contra-hegemônicas, 31(esp.), 244248. doi: https://doi.org/10.22409/1984-0292/v31i_esp/29000

\section{Referências}

AKBAR, Na'im. Papers in african psychology. Flórida: Mind Productions, 1975.

ASANTE, Molefi Kete. Afrocentricidade: notas sobre uma posição disciplinar. In: NASCIMENTO, Elisa (Org.). Afrocentricidade: uma abordagem epistemológica inovadora. São Paulo: Selo Negro. 2009. p. 93-110.

BREUER, Josef; FREUD, Sigmund. Estudos sobre Histeria (1895). Rio de Janeiro: Imago, 1995. v. 2.

CARNEIRO, Sueli. Racismo, sexismo e desigualdade no Brasil. São Paulo: Selo Negro, 2011.

FANON, Frantz. Pele negra, máscaras brancas. Salvador: EDUFBA, 2008.
GUATTARI, Félix. Caosmose. São Paulo: Editora 34, 1992.

MIGNOLO, Walter. Desobediência epistêmica: a opção descolonial e o significado de identidade em política. Cadernos de Letras da UFF: Dossiê: Literatura, língua e identidade, Niterói, n. 34, p. 287-324, 2008. Disponível em: http://www. cadernosdeletras.uff.br/joomla/images/stories/edicoes/34/ traducao.pdf. Acesso em: 20 jun. 2018.

MBEMBE, Achille. Políticas da inimizade. Lisboa: Antígona, 2017.

MOMBAÇA, Jota. Rumo a uma redistribuição desobediente de gênero e anticolonial da violência. Issuu, 2016. Disponível em: https://issuu.com/amilcarpacker/docs/rumo_a_uma redistribuic a o da vi. Acesso em: 17 jan. 2019.

NASCIMENTO, Abdias. Quilombismo: um conceito emergente do processo histórico-cultural da população afrobrasileira. In: NASCIMENTO, Elisa (Org.). Afrocentricidade: uma abordagem epistemológica inovadora. São Paulo: Selo Negro, 2009. p. 197-218.

NASCIMENTO, Beatriz. O conceito de quilombo e a resistência cultural negra. Revista Afrodiáspora, n. 6-7, p. 41-49, 1985.

NIETZSCHE, Friedrich. A gaia ciência (1882). São Paulo: Companhia das Letras, 2012.

NOBLES, Wade. Sakhu Sheti: retomando e reapropriando um foco psicológico afrocentrado. In: NASCIMENTO, Elisa. (Org.) Afrocentricidade: uma abordagem epistemológica inovadora. São Paulo: Selo Negro, 2009. p. 277-298.

PRAÇA Paris. Roteiro: Lucia Murat e Raphael Montes. Direção: Lucia Murat. Produção: Felicitas Rafo, Lucia Murat e Luís Galvão Telles. Intérpretes: Grace Passô, Joana de Verona, Babu Santana, Daniel Braga. Música: André Abujamra e Márcio Nigro. Brasil: Imovision, 2018. 1 DVD (110 min.), color.

SOUZA, Neusa Santos. Tornar-se negro. Rio de Janeiro: Graal, 1983.

VEIGA, Lucas Motta. O analista está presente: a arte da performance de Marina Abramovic e a clínica. Dissertação (Mestrado em Psicologia). 2015. 75 f. Programa de Pósgraduação em Psicologia da Universidade Federal Fluminense, Niterói, 2015. Disponível em: https:/app.uff.br/slab/ uploads/2015_d_Lucas.pdf. Acesso em: 17 jan. 2019.

VEIGA, Lucas Motta. Qual a cor da Psicologia no Brasil? Jornal do Brasil, Rio de Janeiro, RJ, 9 set. 2018a. Opinião, p. 9. Disponível em: https://www.jb.com.br/pais/ artigo/2018/09/4697-qual-a-cor-da-psicologia-no-brasil.html. Acesso em: 16 dez. 2018.

VEIGA, Lucas Motta. As diásporas da bixa preta: sobre ser negro e gay no Brasil. Revista Tabuleiro de Letras, Salvador, v. 12, n. 1, p. 77-88, 2018b. http://dx.doi.org/10.35499/ tl.v12i1.5176

Fractal, Rev. Psicol., v. 31 - n. esp., p. 244-248, set. 2019 